\title{
Defect in Biosynthesis of Mitochondrial Acetoacetyl-Coenzyme A Thiolase in Cultured Fibroblasts from a Boy with 3-Ketothiolase Deficiency
}

\author{
Seiji Yamaguchi," Tadao Orii, " Nobuo Sakura," Shoko Miyazawa, ${ }^{5}$ and Takashi Hashimoto \\ ${ }^{*}$ Department of Pediatrics, Gifu University School of Medicine, Gifu 500, Japan; ${ }^{\ddagger}$ Department of Pediatrics, \\ Hiroshima University School of Medicine, Hiroshima 734, Japan; and ${ }^{\S}$ Department of Biochemistry, \\ Shinshu University School of Medicine, Matsumoto, Nagano 390, Japan
}

\begin{abstract}
The etiology of 3-ketothiolase deficiency has been attributed to a defect of mitochondrial acetoacetyl-CoA thiolase because the acetoacetyl-CoA thiolase activity in related materials is not activated by $\mathrm{K}^{+}$, a property characteristic for this enzyme. We studied the enzyme protein and the biosynthesis of mitochondrial acetoacetyl-CoA thiolase, using cultured skin fibroblasts from a 5-yr-old boy with 3-ketothiolase deficiency. The following results were obtained. (a) Activation of acetoacetyl-CoA thiolase activity by $\mathrm{K}^{+}$was nil; (b) The enzyme activity was not affected by treatment with the antibody against mitochondrial acetoacetyl-CoA thiolase; (c) A signal for mitochondrial acetoacetyl-CoA thiolase protein was not detected in the immunoblot analysis; and $(d)$ Pulse-chase experiments of skin fibroblasts, using ${ }^{35}$ S]methionine, revealed no incorporation of radioactivity into this enzyme. Therefore, fibroblasts from this patient lacked mitochondrial acetoacetyl-CoA thiolase protein due to a defect in its biosynthesis.
\end{abstract}

\section{Introduction}

3-Ketothiolase deficiency is an inherited metabolic disorder of organic acids in which characteristic organic acids such as 2methyl-3-hydroxybutyric acid, 2-methylacetoacetic acid, and tiglylglycine are present in the urine $(1-12)$. The first report of this disease was apparently that of Daum et al. (1), who described it as an inherited disorder of isoleucine catabolism. Later, it was found that this disease is not simply a defect of isoleucine degradation and that the deficient enzyme is the $\mathrm{K}^{+}$-dependent short chain mitochondrial thiolase, which plays a major role in ketone body metabolism (6). It was also reported that mitochondrial acetoacetyl-CoA thiolase (EC 2.3.1.9) acts on 2-methylacetoacetyl-CoA and that no activity with this substrate is observed in fibroblast extracts of patients with 3-ketothiolase deficiency (7-11). Although the deficient activity of mitochondrial acetoacetyl-CoA thiolase in such patients has been confirmed $(7,8,10,11)$, further data on the enzyme protein were not reported. There are at least four thiolases in mammalian tissues: cytosolic acetoacetyl-CoA thiolase, mitochondrial acetoacetyl-CoA thiolase, mitochondrial 3-ketoacyl-CoA thiolase, and peroxisomal 3-ketoacyl-

Address reprint requests to Dr. Yamaguchi, Dept. of Pediatrics, Gifu University School of Medicine, 40 Tsukasa-Machi, Gifu 500, Japan.

Received for publication 18 May 1987 and in revised form 30 September 1987.

J. Clin. Invest.

(C) The American Society for Clinical Investigation, Inc.

$0021-9738 / 88 / 03 / 0813 / 05 \$ 2.00$

Volume 81, March 1988, 813-817
CoA thiolase $(13,14)$. These enzymes can be distinguished using antibodies. We now report the absence of mitochondrial acetoacetyl-CoA thiolase protein in cultured skin fibroblasts from a boy with 3-ketothiolase deficiency, which was apparently due to a defect in the biosynthesis of this protein.

\section{Methods}

Patient and fibroblasts. The patient was a 5-yr-old Japanese boy, born in 1981. The diagnosis of 3-ketothiolase deficiency had been based on the results of gas chromatography-mass spectrophotometry analysis of urinary organic acids when the boy was $20 \mathrm{mo}$ of age. A case report of this patient has been published (12). There was a large amount of 2-methyl-3-hydroxybutyric acid and a smaller amount of 2-methylacetoacetic acid and tiglylglycine, regardless of the degree of ketonuria, in all samples examined. Skin fibroblasts were grown in Eagle's minimum essential medium containing $10 \%$ fetal calf serum (volume/volume) and antibiotics (standard medium). The cells were used 3-4 d after confluency.

Materials. Acetoacetyl-CoA and 3-ketooctanoyl-CoA were prepared as described (14). CoA and protein A-Sepharose were purchased from Sigma Chemical Co., St. Louis, MO. $\left[{ }^{35}\right.$ S]Methionine (> 1,000 $\mathrm{Ci} / \mathrm{mmol}$ ), rabbit reticulocyte lysate, and Amplify were from Amersham Corp., Arlington Heights, IL. Affinity adsorbent was from Boehringer Mannheim Biochemicals, Indianapolis, IN, and the protease inhibitors were from the Peptide Institute (Osaka, Japan). The fixed Staphylococcus aureus cells was from Sanraku Co. (Tokyo, Japan), and the immunoblotting system was from Promega Biotec, Madison, WI.

Mitochondrial acetoacetyl-CoA thiolase and mitochondrial and peroxisomal 3-ketoacyl-CoA thiolases were purified from rat liver and the antibodies were raised in rabbits, as described (14). The antibodies were immunopurified with the use of immunoadsorbent columns coupled with the enzymes, as described in the instructions from the manufacturer. The monospecificities of the antibody preparations against human liver thiolases were tested by titration of the enzymes and immunoblot analysis. Human enzymes were purified from the autopsied liver. The liver extract was applied successively onto the columns of DEAE-cellulose and phosphocellulose, as described for the purification of the rat thiolases (14). Mitochondrial acetoacetyl-CoA thiolase was purified into a nearly homogeneous preparation, using essentially the same procedure described for the rat enzymes (14). The fractions containing 3-ketoacyl-CoA thiolases, monitored by the thiolase activity with 3-ketooctanoyl-CoA in the first phosphocellulose column chromatography, were pooled and concentrated by precipitation with $\left(\mathrm{NH}_{4}\right)_{2} \mathrm{SO}_{4}(600 \mathrm{~g} /$ liter). After desalting, a second phosphocellulose column chromatography was carried out at $\mathrm{pH}$ 8.0. Fractions with the highest specific activity were treated with $\left(\mathrm{NH}_{4}\right)_{2} \mathrm{SO}_{4}$. The precipitate was dissolved in a small volume of $10 \mathrm{mM}$ sodium phosphate, $\mathrm{pH} 8.0$, containing $5 \%$ glycerol (volume/volume) and $5 \mathrm{mM}$ $\beta$-mercaptoethanol, and was passed through a Sephadex G-100 column that had been equilibrated with the same buffer. The first few fractions of the activity peak contained highly purified mitochondrial 3-ketoacyl-CoA thiolase with no detectable peroxisomal enzyme, and the latter fractions contained both mitochondrial and peroxisomal 
enzymes. The last few fractions containing largely the peroxisomal enzyme were subjected to molecular sieving to remove most of the mitochondrial enzyme. Cytosolic acetoacetyl-CoA thiolase was purified according to Middleton (15). All of the purified enzyme preparations were dialyzed against $10 \mathrm{mM}$ sodium phosphate, $\mathrm{pH} 8.0$, containing $50 \%$ glycerol vol/vol and $5 \mathrm{mM} \beta$-mercaptoethanol, and were then stored at $-20^{\circ} \mathrm{C}$.

Enzyme assay and immunotitration. The attached fibroblasts were washed with sodium phosphate-buffered saline and harvested in a volume of $50 \mathrm{mM}$ sodium phosphate, $\mathrm{pH} 7.5 / 1 \mathrm{mM}$ dithiothreitol/ $0.1 \%$ Triton X-100/protease inhibitors ( $10 \mathrm{mg}$ each per milliliter, antipain, bestatin, chymostatin, pepstatin, phosphoramidon, and E-64). The suspension was sonicated and centrifuged at $10,000 \mathrm{~g}$ for $10 \mathrm{~min}$. The supernatant was used for the enzyme assay within one day, and the remaining solution was preserved for protein determination and immunoblot analysis.

The enzyme assay was conducted as described (14) and the activity with acetoacetyl-CoA thiolase was determined, with and without $\mathrm{K}^{+}$ $(50 \mathrm{mM} \mathrm{KCl})$. Units of enzyme activity were expressed as millimoles of the substrate utilized per minute. Protein concentration was determined by a modification (16) of the method of Lowry et al. (17).

In the immunotitration experiment, the fibroblast extracts $(50 \mu \mathrm{l}$, $\sim 5 \mathrm{mg} / \mathrm{ml}$ of protein) were mixed with the antibodies fivefold or more the equivalent amount, as estimated from the minimal quantity of the antibody required to decrease the remaining activity in the supernatant to zero, after incubation of various amounts of the purified human enzymes with fixed amounts of the antibodies) and bovine serum albumin (final concentration of $2 \mathrm{mg} / \mathrm{ml}$ ) in a volume of $120 \mu \mathrm{l}$ and the preparation then incubated at room temperature for $30 \mathrm{~min}$. The mixture was added to $80 \mu \mathrm{l}$ of a $20 \%$ protein A-Sepharose suspension and shaken at room temperature for $60 \mathrm{~min}$. All of the components, except the fibroblast extracts, were present in $150 \mathrm{mM} \mathrm{NaCl} / 10$ $\mathrm{mM}$ sodium phosphate, $\mathrm{pH}$ 7.5. The suspension was centrifuged at $10,000 \mathrm{~g}$ for $5 \mathrm{~min}$ and the supernatant was used for the enzyme assay.

Immunoblot analysis. The fibroblast extracts were subjected to SDS-PAGE using a $10 \%$ gel (18). Immunoblot analysis was performed according to Towbin et al. (19) using an immunoblotting system for color development.

Pulse-chase experiment. The fibroblasts were grown in a $20-\mathrm{cm}^{2}$ dish for the pulse-chase experiment. The cells were washed twice with methionine-depleted Eagle's minimum essential medium containing $5 \%$ dialyzed fetal calf serum (volume/volume), and then incubated for $1 \mathrm{~h}$ in the same medium. The medium was replaced with $1 \mathrm{ml}$ of the same medium containing $100 \mu \mathrm{Ci}$ of $\left[{ }^{35} \mathrm{~S}\right]$ methionine. After a 1-h pulse, the medium was replaced with the standard medium and the preparation chased for 6 and $24 \mathrm{~h}$, respectively. The labeled cells were rapidly washed three times with phosphate-buffered saline and collected in a volume of $10 \mathrm{mM}$ Tris-Cl, $\mathrm{pH} 7.4 / 2 \mathrm{mM}$ EDTA/0.1\% SDS/0.1\% Triton X-100/0.1\% bovine serum albumin/ $10 \mathrm{mM}$ methionine/ $0.02 \% \mathrm{NaN}_{3} /$ protease inhibitors. The suspension was sonicated and centrifuged at $10,000 \mathrm{~g}$ for $10 \mathrm{~min}$, and the supernatant was preserved for immunoprecipitation.

The cell-free translation was conducted with free polysomes from rat liver (20) according to the manufacturerer's instructions. The reaction was halted by adding $1 \mathrm{ml}$ of $10 \mathrm{mM}$ Tris-Cl, pH 7.4/2 mM EDTA $/ 0.1 \%$ SDS/0.1\% Triton X-100/10 mM methionine.

Labeled enzymes in the fibroblast extracts and the cell-free translation products were immunoprecipitated with the antibodies and $50 \mu \mathrm{l}$ of $20 \%$ of fixed $S$. aureus cells (weight/volume). The recovered labeled products were subjected to SDS-PAGE and fluorography. Competition experiments were done using an excess amount of the purified rat enzymes during the immunoprecipitation.

\section{Results}

Enzyme activity. Both the rat mitochondrial and cytosolic acetoacetyl-CoA thiolases are specific for acetoacetyl-CoA and exhibited no activity with 3-ketooctanoyl-CoA. Mitochondrial 3-ketoacyl-CoA thiolase has a relatively broad substrate specificity and the ratio of the activity with 3-ketooctanoylCoA to that with acetoacetyl-CoA is $\sim 4$, whereas that of peroxisomal 3-ketoacyl-CoA thiolase is $\sim 20(13,14)$. The substrate specificities of the human liver enzymes proved to be similar to those of the rat enzymes. Human mitochondrial acetoacetyl-CoA thiolase is activated about eightfold in the presence of $50 \mathrm{mM} \mathrm{KCl}$ (the presence of $1 \mathrm{mM} \mathrm{K}^{+}$causes half-maximal activation). The other thiolase activities were not affected by the addition of $\mathrm{K}^{+}$, as was the case with the corresponding rat enzymes $(14,15)$.

Thiolase activities of the fibroblast extracts are summarized in Table I. The thiolase activity with acetoacetyl-CoA in the control fibroblasts was activated about 2-fold but that of the patient's fibroblasts was unaffected by $\mathrm{K}^{+}$. The thiolase activity with 3-ketooctanoyl-CoA was much the same for both the controls and the patient.

Immunotitration. The fibroblast extracts were treated with the antibodies and the remaining thiolase activities were measured with acetoacetyl-CoA and 3-ketooctanoyl-CoA (Table II). When the control fibroblast extracts were treated with anti-(mitochondrial acetoacetyl-CoA thiolase) IgG, the activation by $\mathrm{K}^{+}$of acetoacetyl-CoA thiolase activity disappeared. However, the acetoacetyl-CoA thiolase activity of the patient's fibroblasts remained unchanged after treatment with the antibody. The acetoacetyl-CoA thiolase activities of both the control and the patient fibroblasts were decreased after treatment with anti-(mitochondrial 3-ketoacyl-CoA thiolase) IgG. A large part of the activity with 3-ketooctanoyl-CoA was titrated by anti-(mitochondrial 3-ketoacyl-CoA thiolase) IgG, in both the control and the patient's fibroblasts, and the acetoacetylCoA thiolase activity was also decreased. The thiolase activity was all but unchanged before and after treatment with anti-(peroxisomal 3-ketoacyl-CoA thiolase) IgG in both the control and the patient's fibroblasts. In separate experiments, we used the purified human and rat thiolases and sufficient amounts of their antibodies (fivefold or more the equivalent amount). The enzymes were not completely titrated under the standard conditions: $\sim 10 \%$ of the activities remained. However, when the mixtures were shaken without the antibodies, the enzyme activity of all of the enzymes gradually decreased after $60 \mathrm{~min}$. Therefore, the mixtures of the fibroblast extracts

Table I. Thiolase Activity of Skin Fibroblasts

\begin{tabular}{lccccc}
\hline & \multicolumn{4}{c}{ Enzyme activity (mU/mg protein) with: } & \\
\cline { 2 - 4 } & \multicolumn{3}{c}{ Acetoacetyl-CoA (C4) } & C8/C4 \\
\cline { 2 - 4 } & $+\mathrm{K}^{+}$ & $-\mathrm{K}^{+}$ & $+\mathrm{K}^{+} /-\mathrm{K}^{+}$ & $\begin{array}{c}\text { 3-Ketooctanoyl- } \\
\text { CoA (C8) }\end{array}$ & \\
\hline Patient & 4.6 & 4.4 & 1.0 & 12.5 & 2.7 \\
Control 1 & 7.8 & 3.7 & 2.1 & 8.3 & 1.1 \\
Control 2 & 9.6 & 5.3 & 1.8 & 12.4 & 1.3 \\
Control 3 & 8.0 & 3.8 & 2.1 & 9.5 & 1.2 \\
& & & & & \\
\hline
\end{tabular}

The acetoacetyl-CoA thiolase activity was determined in the presence $\left(+\mathrm{K}^{+}\right)$or absence $\left(-\mathrm{K}^{+}\right)$of $\mathrm{K}^{+}$and the ratio of these two activities $\left(+\mathrm{K}^{+} /-\mathrm{K}^{+}\right)$are listed. The activity with 3-ketooctanoyl-CoA was determined in the presence of $\mathrm{K}^{+}$. The ratios of the activities with these two substrates in the presence of $\mathrm{K}^{+}$were calculated $(\mathrm{C} 8 / \mathrm{C} 4)$. 
Table II. Immunotitration of Thiolase Activity of the Fibroblasts

\begin{tabular}{|c|c|c|c|c|}
\hline \multirow[b]{3}{*}{ Antibody } & \multicolumn{4}{|c|}{ Enzyme activity $(m U / m g$ protein) with: } \\
\hline & \multicolumn{3}{|c|}{ Acetoacetyl-CoA } & \multirow{2}{*}{$\begin{array}{c}\text { 3-Ketooctanoyl- } \\
\text { CoA }\end{array}$} \\
\hline & $+\mathrm{K}^{+}$ & $-\mathbf{K}^{+}$ & $+\mathrm{K}^{+} /-\mathrm{K}^{+}$ & \\
\hline \multicolumn{5}{|l|}{ Patient } \\
\hline None & 6.7 & 6.9 & 1.0 & 15.3 \\
\hline Anti-T1 & 2.3 & 2.4 & 1.0 & 4.0 \\
\hline Anti-T2 & 6.7 & 7.0 & 1.0 & 15.3 \\
\hline Anti-PT & 6.5 & 6.5 & 1.0 & 15.4 \\
\hline Anti-T1, -T2, and -PT & 2.4 & 2.3 & 1.0 & 3.9 \\
\hline \multicolumn{5}{|l|}{ Control } \\
\hline None & 8.0 & 4.5 & 1.8 & 8.2 \\
\hline Anti-T1 & 6.0 & 2.9 & 2.1 & 2.5 \\
\hline Anti-T2 & 4.8 & 4.6 & 1.0 & 7.5 \\
\hline Anti-PT & 8.0 & 4.8 & 1.7 & 7.7 \\
\hline Anti-T1, -T2, and -PT & 3.0 & 2.8 & 1.1 & 2.0 \\
\hline
\end{tabular}

The fibroblast extracts were treated with the antibodies, as described in Methods. Abbreviations for the antibodies used in this Table are: anti-T1, anti-(mitochondrial 3-ketoacyl-CoA thiolase)IgG; anti-T2, anti-(mitochondrial acetoacetyl-CoA thiolase)IgG; and anti-PT, anti-(peroxisomal 3-ketoacyl-CoA thiolase)IgG. The other abbreviations are the same as for Table I.

and antibodies were shaken with protein A-Sepharose for 60 min as described in Methods. Most of the remaining acetoacetyl-CoA activity after treatment with the three antibodies may be due to cytosolic acetoacetyl-CoA thiolase.

Immunoblot analysis. Fig. 1 shows the results of SDSPAGE of the purified rat and human liver enzymes. The human mitochondrial acetoacetyl-CoA thiolase (Fig. 1, lane 2) migrated at a slightly higher rate than the rat enzyme (Fig. 1, lane 1), whereas the human mitochondrial 3-ketoacyl-CoA thiolase (Fig. 1, lane 4) migrated at a slightly lower rate than

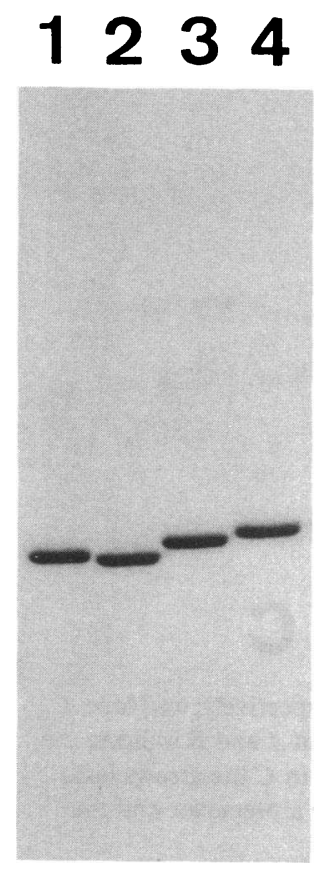

Figure 1. SDS-PAGE of rat and human liver mitochondrial thiolases. The enzymes were purified as described in Methods. Lanes 1 and 2 are rat and human mitochondrial acetoacetyl-CoA thiolases, respectively. Lanes 3 and 4 are rat and human mitochondrial 3-ketoacylCoA thiolases, respectively. $1 \mathrm{mg}$ of the proteins was used. the rat enzyme (Fig. 1, lane 3). We examined the molecular sizes of the subunits of these thiolases by immunoblot analysis, using purified rat liver enzyme preparations and freshly prepared homogenates of human liver and fibroblasts with a buffer containing protease inhibitors. The positions of the signals for the homogenates were the same as those for the corresponding purified enzymes. These findings indicated that differences in the electrophoretic mobilities of these purified preparations are not due to proteolytic modification during the purification.

Fig. 2 summarizes the results of immunoblot analysis of the three thiolases. The signal for the purified human liver mitochondrial acetoacetyl-CoA thiolase (Fig. $2 A$, lane 2, $10 \mathrm{ng}$ of protein used) appeared to exhibit nearly the same intensity as that of the rat enzyme (Fig. $2 A$, lane $1,2 \mathrm{ng}$ of protein used). The signals of mitochondrial acetoacetyl-CoA thiolase for the control (Fig. $2 A$, lanes 3 and 5), but not for the patient's fibroblasts (Fig. $2 A$, lane 4 ), were apparent. In a separate experiment, a large amount of the patient's sample and various amounts of the purified enzyme were examined and the intensities of the signals were compared. The content of this enzyme in the patient's fibroblasts was estimated to be $<2 \%$ of the control. On the other hand, signals for mitochondrial and peroxisomal 3-ketoacyl-CoA thiolases were detected in both the control and the patient's fibroblasts, as shown in Fig. 2, B and $C$, respectively. In another separate experiment, these three antibody preparations were found to have no crossreactivity for each of the other purified thiolases, including cytosolic acetoacetyl-CoA thiolase. Other mitochondrial proteins were also examined by immunoblot analysis: short-chain and medium-chain acyl-CoA dehydrogenases (EC 1.3.99.2 and EC 1.3.99.3); electron transferring flavoprotein; enoyl-CoA hydratase (EC 4.2.1.17); and 3-hydroxyacyl-CoA dehydrogenase (EC 1.1.1.35). The intensities of the immunoblot signals for these proteins in the patient's fibroblasts were much the same as those for the controls (not shown). These results indicate that the patient's fibroblasts were defective only of mitochondrial acetoacetyl-CoA thiolase protein, among the mitochondrial proteins tested.

Pulse-chase experiment. Mitochondrial acetoacetyl-CoA thiolase was pulse-labeled for $1 \mathrm{~h}$, and then chased for 6 and 24 h. The fluorographic bands at 1-h pulse, 6- and 24-h chase were apparent in the control fibroblasts (Fig. $3 \mathrm{~A}$, lanes $1-3$ of the control). However, no fluorographic band was observed in the patient's fibroblasts (Fig. $3 A$, lanes $1-3$ of the patient). The labeled products were identified by the experiment in which the radioactive band disappeared with the addition of the purified rat enzyme (Fig. 2, lane 4). The fluorographic bands for both mitochondrial and peroxisomal 3-ketoacyl-CoA thiolases were detected in both the control and the patient's fibroblasts (Fig. 3, $B$ and $C$ ). These results indicate that the patient's fibroblasts had a defect in the biosynthesis of mitochondrial acetoacetyl-CoA thiolase, but not in those of 3-ketoacyl-CoA thiolases.

It was reported that the cell-free translation products of rat liver mitochondrial acetoacetyl-CoA thiolase and peroxisomal 3-ketoacyl-CoA thiolase were larger than the subunits of the corresponding mature enzymes (21), but the cell-free translation products of mitochondrial 3-ketoacyl-CoA thiolase could not be distinguished from that of the mature enzyme $(22,23)$. In $A$ of Fig. 3, the position of the fluorographic bands for mitochondrial acetoacetyl-CoA thiolase in lanes $1-3$ of the 


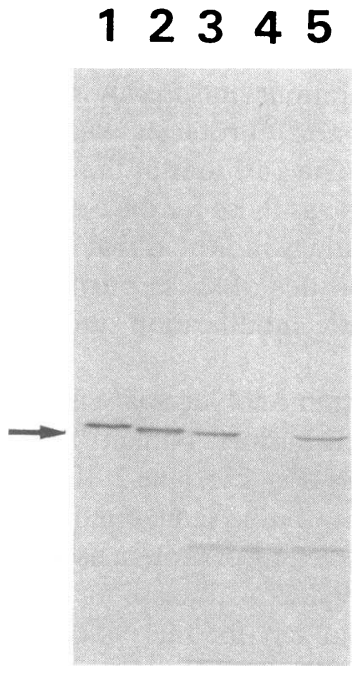

A

Figure 2. Immunoblot analysis of thiolase proteins in skin fibroblasts. $(A)$ Mitochondrial acetoacetyl-CoA thiolase; lane 1 , rat enzyme $(2 \mathrm{ng})$; lane 2, human enzyme (10 $\mathrm{ng})$; lanes 3 and 5 , control fibroblasts ( $40 \mathrm{mg}$ of proteins); lane 4 , patient's fibroblasts ( $40 \mathrm{mg}$ of proteins). (B) Mitochondrial 3-ketoacyl-CoA thiolase; lane 1, rat enzyme (1 ng); lane 2, human enzyme ( $5 \mathrm{ng})$; lanes 3 and 5 , control fibroblasts ( $40 \mathrm{mg}$ of proteins); lane 4, patient's fibroblasts ( $40 \mathrm{mg}$ of proteins). (C) Peroxisomal 3-ketoacyl-CoA thiolase; lane 1, rat enzyme ( $1 \mathrm{ng}$, estimated from the enzyme activity); lane 2, human enzyme ( $1 \mathrm{ng}$, estimated from the enzyme activity); lanes 3 and 5 , control fibroblasts ( $80 \mathrm{mg}$ of proteins); lane 4, patient's fibroblasts ( $80 \mathrm{mg}$ of proteins). Arrows indicate the signals identified as each thiolase protein in the fibroblasts. The faster bands evident in lanes 3-5 of $A$ may be due to the nonspecific reaction.

control in Fig. 3 was at much the same position as that of the subunit of the purified human enzyme, and no fluorographic band suspected to be the precursor was detected. We did not perform a cell-free translation experiment with the use of a human RNA preparation. When the cell-free translation experiment with the use of free polysomes of the rat liver was done for comparison (Fig. 3, lane 0 ), the position of the fluorographic band differed from that of the purified rat enzyme. The intense fluorographic band suspected to be a precursor of peroxisomal 3-ketoacyl-CoA thiolase was observed at a 1-h pulse and a faint band remained even at a $6-\mathrm{h}$ chase. The long life of this precursor has been reported (24).

\section{Discussion}

Measuring the activation by $\mathrm{K}^{+}$of the acetoacetyl-CoA thiolase activity has been done in studies on 3-ketothiolase deficiency $(6,10-12)$, since this property is one of the characteristic features of mitochondrial acetoacetyl-CoA thiolase. This procedure revealed that cells derived from patients with 3-ketothiolase deficiency have no component of $\mathrm{K}^{+}$-activation of the thiolase activity. It has been claimed that this disorder is due to a deficient activity of mitochondrial acetoacetyl-CoA thiolase.

We used antibodies to study mechanisms related to the

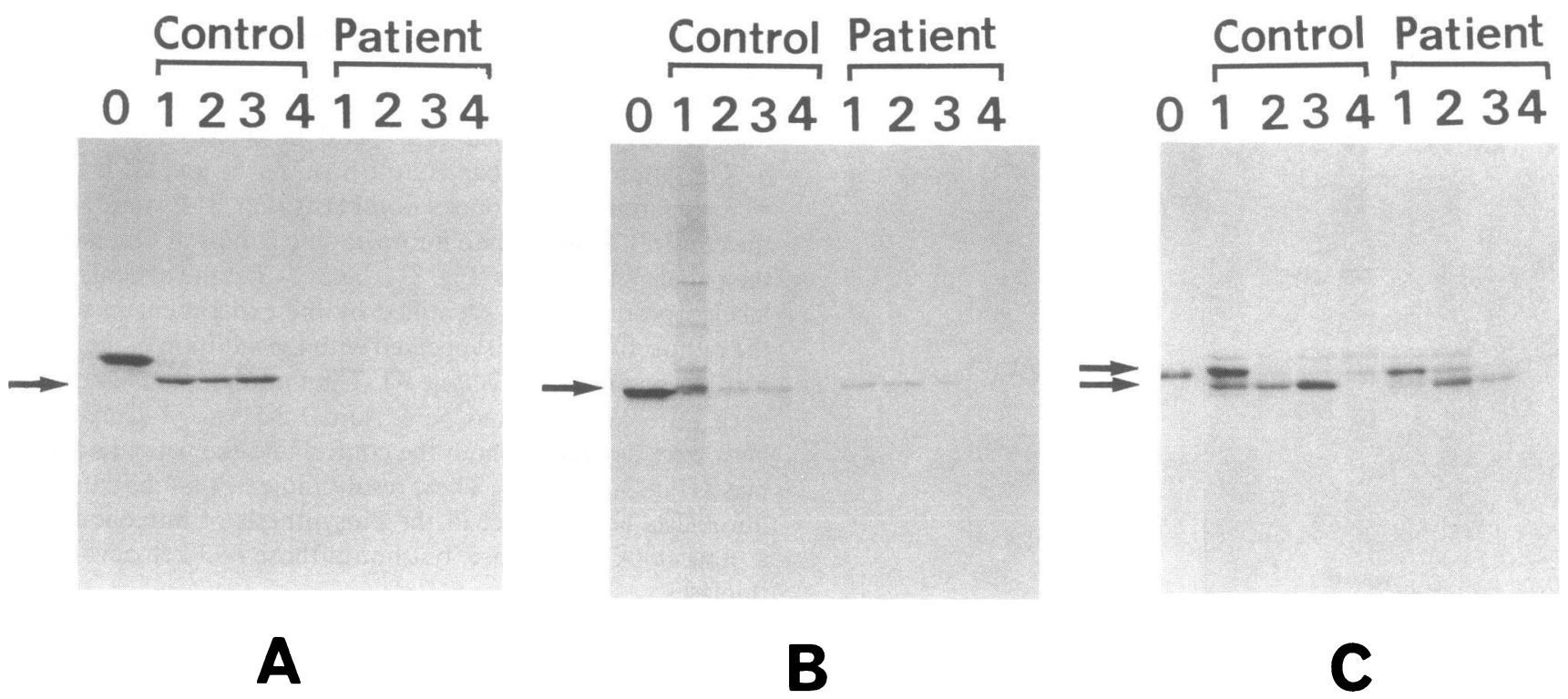

Figure 3. Pulse labeling and chase of thiolases in fibroblasts. Pulsechase experiments were conducted, as described in Methods. $(A) \mathrm{Mi}-$ tochondrial acetoacetyl-CoA thiolase; $(B)$ mitochondrial 3-ketoacylCoA thiolase; $(C)$ peroxisomal 3-ketoacyl-CoA thiolase. Lane 0 , cellfree translation products with free polysomes from rat liver; lane 1 , 1-h pulse; lanes 2 and 3, 6- and 24-h chase, respectively; and lane 4 , competition experiment of 1-h pulse. Arrows in $A$ and $B$ indicate the positions of the purified human enzymes, and in $C$ the arrows indicate the positions of the bands suspected to be a precursor and the subunit of the mature enzyme, respectively. 
deficient activity, because antibodies against rat thiolases were confirmed to be crossreactive with human enzymes. Skin fibroblasts from the patient had no component of $\mathrm{K}^{+}$-dependent acetoacetyl-CoA thiolase activity. This component present in the control fibroblasts disappeared after treatment with the antibody against mitochondrial acetoacetyl-CoA thiolase. The signal for this enzyme by immunoblot analysis was clearly observed for the control fibroblasts but was absent for the patient's fibroblasts. However, the other thiolases and some mitochondrial matrix enzymes were confirmed to exist in the patient's fibroblasts as well as in the controls. Therefore, we concluded that the fibroblasts from a patient with 3-ketothiolase deficiency have no mitochondrial acetoacetyl-CoA thiolase protein, because of a defect in the biosynthesis of this protein.

Mitochondrial acetoacetyl-CoA thiolase is synthesized on free polysomes, transported into mitochondria, and converted to the mature enzyme (22). Therefore, it remains to be determined whether the precursor of this enzyme is synthesized or not in the patient's fibroblasts, because the precursor protein was not clearly evident even in the control fibroblasts. Two species of mitochondrial acetoacetyl-CoA thiolase A and B were noted in the rat liver, as based on the observation that two activity peaks for this enzyme were found on the phosphocellulose column chromatography during purification of the enzyme $(13,14)$. The antibody preparation used reacted with both $A$ and B species (14). Therefore, we are now attempting to determine whether A and B species are a different protein and which enzyme form of these species is lacking in the fibroblasts.

\section{Acknowledgments}

We are grateful to Prof. M. Mori and Dr. M. Takiguchi (Kumamoto University) for the generous gift of the free polysome preparation of the liver. We also thank M. Ohara (Kyushu University) for comments on the manuscript.

This study was supported in part by grants for investigation of psychosomatic disorders from the Ministry of Health and Welfare, and for the promotion of science research $(60770701,61440044$, and Special Project Research Grant 60127010 [inborn errors of metabolism]) from the Ministry of Education, Science and Culture of Japan.

\section{References}

1. Daum, R. S., P. H. Lamm, O. A. Mamer, and C. R. Scriver. 1971. A "new" disorder of isoleucine catabolism. Lancet. ii:12891290.

2. Daum, R. S., C. R. Scriver, O. A. Mamer, E. Devlin, P. Lamm, and H. Goldman. 1973. An inherited disorder of isoleucine catabolism causing accumulation of $\alpha$-methylacetoacetate and $\alpha$-methyl- $\beta$-hydroxybutyrate, and intermittent metabolic acidosis. Pediatr. Res. 7:149-160.

3. Gompertz, D., J. M. Saudubray, C. Charpentier, K. Bartlett, P. A. Goodey, and G. H. Draffan. 1974. A defect in 1-isoleucine metabolism associated with $\alpha$-methyl- $\beta$-hydroxybutyric and $\alpha$ methyl-acetoacetic aciduria: quantitative in vivo and in vitro studies. Clin. Chim. Acta. 57:269-281.

4. Hillman, R. E., and J. P. Keating. 1974. Beta-ketothiolase deficiency as a cause of the "ketotic hyperglycinemia syndrome". Pediatrics. 53:221-225.

5. Halvorsen, S., O. Stokke, and E. Jellum. 1979. A variant form of 2-methyl-3-hydroxybutyric and 2-methylacetoacetic aciduria. Acta Paediatr. Scand. 68:123-128.
6. Robinson, B. H., W. G. Sherwood, J. Taylor, J. W. Balfe, and O. A. Mamer. 1979. Acetoacetyl CoA thiolase deficiency. A cause of severe ketoacidosis in infancy simulating salicylism. J. Pediatr. 95:228-233.

7. Schutgens, R. B. H., B. Middleton, J. F. Blij, J. W. E. Oorthuys, H. A. Veder, T. Vulsma, and W. H. H. Tegelaers. 1982. Beta-ketothiolase deficiency in a family confirmed by in vitro enzymatic assays in fibroblasts. Eur. J. Pediatr. 139:39-42.

8. Middleton, B., and K. Bartlett. 1983. The synthesis and characterisation of 2-methylacetoacetyl coenzyme $A$ and its use in the identification of the site of the defect in 2-methylacetoacetic and 2-methyl3-hydroxybutyric aciduria. Clin. Chim. Acta. 128:291-305.

9. Bennett, M. J., J. M. Littlewood, A. MacDonald, R. J. Pollitt, and J. Thompson. 1983. A case of $\beta$-ketothiolase deficiency. J. Inherited Metab. Dis. 6:157.

10. Middleton, B., R. G. F. Gray, and M. J. Bennett. 1984. Two cases of $\beta$-ketothiolase deficiency: a comparison. J. Inherited Metab. Dis. 7(Suppl. 2):131-132.

11. Middleton, B., K. Bartlett, A. Romanos, J. Gomez Vazquez, C. Conde, R. A. Cannon, M. Lipson, L. Sweetman, and W. L. Nyhan. 1986. 3-Ketothiolase deficiency. Eur. J. Pediatr. 144:586-589.

12. Hiyama, K., N. Sakura, T. Matsumoto, and T. Kuhara. 1986. Deficient beta-ketothiolase activity in leucocytes from a patient with 2-methylacetoacetic aciduria. Clin. Chim. Acta. 155:189-194.

13. Middleton, B. 1973. The oxoacyl-coenzyme A thiolases of animal tissues. Biochem. J. 132:717-730.

14. Miyazawa, S., T. Osumi, and T. Hashimoto. 1980. The presence of a new 3-oxoacyl-CoA thiolase in rat liver peroxisomes. Eur. $J$. Biochem. 103:589-596.

15. Middleton, B. 1974. The kinetic mechanism and properties of the cytosolic acetoacetyl-CoA thiolase from rat liver. Biochem. J. 139:109-121.

16. Markwell, M. A. K., S. M. Haas, L. L. Bieber, and N. E. Tolbert. 1978. A modification of the Lowry procedure to simplify protein determination in membrane and lipoprotein samples. Anal. Biochem. 87:206-210.

17. Lowry, O. H., N. J. Rosebrough, A. L. Farr, and R. J. Randall. 1951. Protein measurement with the Folin phenol reagent. J. Biol. Chem. 193:265-275.

18. Laemmli, U. K. 1970. Cleavage of structural proteins during the assembly of the head of bacteriophage T4. Nature (Lond.). 227:680-685.

19. Towbin, H., T. Staehelin, and J. Gordon. 1979. Electrophoretic transfer of proteins from acrylamide gels to nitrocellulose sheet: procedure and some application. Proc. Natl. Acad. Sci. USA. 76:43504354.

20. Takiguchi, M., M. Mori, and M. Tatibana. 1985. A simple and rapid procedure for high yield isolation of essentially undegraded free and membrane-bound polysomes from rat liver. J. Biochem. 97:1447-1459.

21. Tager, J. M., W. A. Ten Harmsen van der Beek, R. J. A Wanders, T. Hashimoto, H. S. A. Heymans, H. van den Bosch, R. B. H. Schutgens, and A. W. Sohram. 1985. Peroxisomal $\beta$-oxidation enzyme proteins in the Zellweger syndrome. Biochem. Biophys. Res. Commun. 126:1269-1275.

22. Ozasa, H., S. Furuta, S. Miyazawa, T. Osumi, T. Hashimoto, M. Mori, S. Miura, and M. Tatibana. 1984. Biosynthesis of enzymes of rat-liver mitochondrial $\beta$-oxidation. Eur. J. Biochem. 144:453-458.

23. Miura, S., M. Mori, M. Takiguchi, M. Tatibana, S. Furuta, S. Miyazawa, and T. Hashimoto. 1984. Biosynthesis and intracellular transport of enzymes of peroxisomal $\beta$-oxidation. J. Biol. Chem. 259:6397-6402.

24. Schram, A. W., A. Strijland, T. Hashimoto, R. J. A. Wanders, R. B. H. Schutgens, H. van den Bosch, and J. M. Tager. 1986. Biosynthesis and maturation of peroxisomal $\beta$-oxidation enzymes in fibroblasts in retardation to the Zellweger syndrome and infantile Refsum disease. Proc. Natl. Acad. Sci. USA. 83:6156-6158. 